\title{
Decolorization and detoxification of triphenylmethane dyes by isolated endophytic fungus, Bjerkandera adusta SWUSI4 under non-nutritive conditions
}

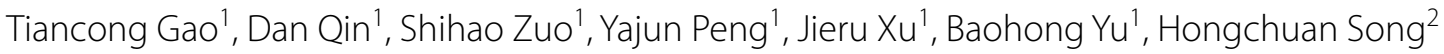
and Jinyan Dong ${ }^{1,3^{*}}$

\begin{abstract}
Biodecolorization by microorganisms is a potential treatment technique because they seem to be environmentally safe. In the present study, the decolorization and detoxification of cotton blue, crystal violet, malachite green and methyl violet by endophytic fungi were investigated. Preliminary screening result indicated that SWUSI4, identified as Bjerkandera adusta, demonstrated the best decolorization for the four TPM dyes within 14 days. Furthermore, optimization result demonstrated the decolorization rate could reach above $90 \%$ at $24 \mathrm{~h}$ by live cells of isolate SWUSI4 when $4 \mathrm{~g}$ biomass was added into $100-\mathrm{mL}$ dyes solution with the concentration $50 \mathrm{mg} / \mathrm{L}$ and shaking $(150 \mathrm{rpm})$ conditions. Moreover, decolorization mechanism analysis shows that the decolorization was caused by the isolate SWUSI4 that mainly includes both absorption of biomass and/or degradation of enzymes. Biosorption of dyes was attributed to binding to hydroxyl, amino, phosphoryl alkane, and ester-lipids groups based on Fourier transform infrared (FTIR) analyses. The biodegradation potential of SWUSI4 was further suggested by the change of peaks in the ultraviolet-visible (UV-vis) spectra and detection of manganese peroxidase and lignin peroxidase activities. Finally, the phytotoxicity test confirmed that the toxicity of TPM dyes after treatment with SWUSI4 was significantly lower than that before treatment. These results indicate that an endophytic SWUSI4 could be used as a potential TPM dyes adsorption and degradation agent, thus facilitating the study of the plant-endophyte symbiosis in the bioremediation processes.
\end{abstract}

Keywords: Triphenylmethane dyes, Bjerkandera adusta SWUSI4, Decolorization, Biodegradation, Phytotoxicity

\section{Introduction}

As one of the most important groups of synthetic dyes, triphenylmethane (TPM) dyes such as cotton blue (CB), crystal violet $(\mathrm{CV})$, malachite green (MG) and methyl violet (MV) in textile, leather, cosmetic, pharmaceutical and paper industries pose a direct threat to the environment due to the toxicity and carcinogenicity of their degradation products (Daneshvar et al. 2007; Chaudhry

\footnotetext{
*Correspondence: donjyaa@swu.edu.cn

${ }^{1}$ Key Laboratory of Eco-Environments in Three Gorges Reservoir Region of Ministry of Education, School of Life Sciences, Southwest University, Chongqing 400715, People's Republic of China

Full list of author information is available at the end of the article
}

et al. 2014; Barapatre et al. 2017; Przystas et al. 2018). As a consequence, effective removal of hazardous TPM dyes from the aqueous solutions as well as detoxification is crucial. Over the past decade, bioremediation is considered an excellent alternative, especially microorganisms such as fungi, since the removal processes occurs by a green technology of low-cost and eco-friendly compared with traditional physico-chemical technique (Kaushik and Malik 2009; Ali 2010; Turhan et al. 2012; Marcharchand and Ting 2017).

There are two main mechanisms by which fungi remove dyes: either biosorption and/or biodegradation (Ali 2010; Marcharchand and Ting 2017; Chen et al. 2019a, b, c). In 
most cases, fungi can degrade dyes, it has been primarily attributed to their enzymes, such as manganese peroxidase (MnP), lignin peroxidase (LiP) and laccase (Lac) (Zhuo et al. 2011; Barapatre et al. 2017; Wang et al. 2017). This has been proven by most widely distributed fungi, for example Phanerochaete chrysosporium (Bumpus and Brock 1988), Trametes versicolor (Casas et al. 2009), Irpex lacteus (Yang et al. 2016), Coriolopsis sp. (Chen and Ting, 2015), Pleurotus ostreatus (Morales-Alvarez et al. 2018).

To the best of our knowledge, many previous studies have focused on using fungi (especially white-rot fungi) to decolorize dyes (Yang et al. 2009; Almeida and Corso 2018). However, the use of endophytic isolates for the decolorization of TPM dyes has been less explored. Endophytic fungi can metabolize organic contaminants and assist in plant growth, thus facilitating the phytoremediation of polluted environments (Shang et al. 2019). Additionally, the application of fungal biomass in dye wastewater treatment technology has attracted more and more attention (Kaushik and Malik 2009; Chen et al. 2019a, b, c). Hence, we can seek potential endophytic fungi for bioremediation of soil, water, etc. Based on the above reasons, the aim of this work was to study the potential use endophytic fungi, which was isolated from the plant, Sinosenecio oldhamianus, as a biological agent to remove TPM dyes. The ability to decolor TPM dyes by endophytic isolate under non-nutritive conditions was evaluated. By studying the effect of decolorization conditions (fungal biomass, initial dye concentration, shaking and static), the UV-vis absorption spectra analysis, Fourier transform infrared (FTIR) analysis, enzyme activities and phytotoxicity, this work may facilitate a better understanding of the role of endophytic fungi in the phytoremediation of TPM dyes.

\section{Material and methods Endophytic fungi}

The endophytic fungi used in this study were isolated from the roots of Sinosenecio oldhamianus. Plant samples were collected from the surrounding areas of factory at Shapingba $\left(106.46^{\circ} \mathrm{E}, 29.65^{\circ} \mathrm{N}\right)$ of Chongqing, China. The samples were chosen randomly, regardless of their age or their size. All samples were immediately brought to the laboratory, and stored at $4{ }^{\circ} \mathrm{C}$ in a refrigerator. Each sample tissues were used within $24 \mathrm{~h}$ from collection for the isolation of endophytic fungi. The endophytic isolations were obtained using the methods described by Huang et al. (2015). Briefly, the roots of Sinosenecio oldhamianus samples were thoroughly washed in running tap water to remove debris, and then air-dried naturally. Subsequently, samples were individually surface sterilized with $75 \%$ ethanol for $5 \mathrm{~min}$ and rinsed with sterile distilled water 3 times, followed by immersion in $0.1 \%$ mercuric chloride ( $\mathrm{HgCl})(\mathrm{v} / \mathrm{v})$ for $3 \mathrm{~min}$. Afterwards, the samples were transferred to potato dextrose agar (PDA) medium (supplemented with $60 \mathrm{mg} / \mathrm{mL}$ of streptomycin and $100 \mathrm{mg} / \mathrm{mL}$ of ampicillin). The inoculated plates were incubated at $28{ }^{\circ} \mathrm{C}$ incubator for $2-15$ days to allow the growth of endophytic fungal hyphae, and checked regularly until pure culture.

\section{Screening of decolorized strains}

The isolated endophytes were grown onto mineral basal medium (MBM) agar plates and preliminary screened for their ability to decolorize four types of TPM dyes (CV, MV, MG and $\mathrm{CB})$. The $\mathrm{MBM}$ contained $(\mathrm{g} / \mathrm{L})$ : $\mathrm{FeSO}_{4} \cdot 7 \mathrm{H}_{2} \mathrm{O}, 0.01 ; \mathrm{ZnSO}_{4} \cdot 7 \mathrm{H}_{2} \mathrm{O}, 0.01 ; \mathrm{MgSO}_{4} \cdot 7 \mathrm{H}_{2} \mathrm{O}$, 0.5; $\mathrm{CuSO}_{4} \cdot 5 \mathrm{H}_{2} \mathrm{O}, 0.05 ; \mathrm{KCl}, 0.5 ; \mathrm{K}_{2} \mathrm{HPO}_{4}, 1 ; \mathrm{NaNO}_{3}, 3$; starch, 10; and agar, 18.

Each TPM dye (CV, MV, MG and CB) was added into the MBM medium to a final concentration of $100 \mathrm{mg} / \mathrm{L}$. The agar plates were inoculated with a $5-\mathrm{mm}^{2}$ agar plug from a 7-day-old fungal culture and incubated in $28{ }^{\circ} \mathrm{C}$ for 14 days and finally the colonies which showed a maximum decolorization zone was obtained. Un-inoculated plates with the respective dyes were used as the control. Each isolate was prepared in triplicate.

\section{Strain identification}

The fungal isolate with the highest decolorization potential against TPM dyes was taxonomically identified based on its morphological characteristic, and also by comparison of the ITS sequences as described in Qin et al. (2018). Briefly, the morphological appearances of the selected fungal isolate were characterized based on mycelium color, growth pattern, and morphology of vegetative spores' structure. For molecular identification, genomic DNA was extracted from $1 \mathrm{~g}$ of chilled mycelia in liquid nitrogen using the CTAB method (Zhang et al. 2006). Extracted fungal DNA was then PCR-amplified using universal primer ITS1 and ITS4 under the following conditions: an initial denaturing step at $94{ }^{\circ} \mathrm{C}$ for $3 \mathrm{~min}$, followed by 32 amplification cycles at $94{ }^{\circ} \mathrm{C}$ for $30 \mathrm{~s}, 56{ }^{\circ} \mathrm{C}$ for $30 \mathrm{~s}, 72{ }^{\circ} \mathrm{C}$ for $90 \mathrm{~s}$, and a final extension at $72{ }^{\circ} \mathrm{C}$ for $10 \mathrm{~min}$. PCR products were then purified and sequenced. The fungi were classified by comparing the ITS sequences of fungi with the data available in NCBI using BLAST search (https://www.ncbi.nlm.nih.gov/). The resulting sequences were aligned with the Clustal $\mathrm{X}$ software (Larkin et al. 2007), with gaps treated as missing data. Phylogenetic tree was built by the neighbor-joining method using Mega 6.0 software. The bootstrap was 1000 replications to assess the reliability of the inferred tree (Tamura et al. 2011). 


\section{Dye decolorization batch experiments under non-nutritive conditions}

Fungal biomass was first established by inoculating $100 \mathrm{~mL}$ potato dextrose broth (PDB) with three mycelium plugs $(0.8 \mathrm{~cm}$ in diameter $)$ to generate sufficient biomass used for dye decolorization experiments. The inoculated PDB was then incubated as a standing culture $\left(28 \pm 2{ }^{\circ} \mathrm{C}\right)$ for $5-7$ days, and the biomass was subsequently filtered through a sterile filter paper, then fresh biomass was harvested and washed with sterile distilled water. Each TPM dye (CV, MV, MG, and CB) was weighed and dissolved in $100 \mathrm{~mL}$ autoclaved distilled water to produce dye solutions. To analyze the effects of different conditions on the efficiency of TPM dyes decolorization, batch experiments were conducted at different fungal biomass inoculum size (1-8 g), initial dyes concentrations (50-250 mg/L), static (0 rpm) and shaking (150 rpm) conditions using decolorization percentage as the index. Untreated (non-inoculated) dye solutions were designed as controls. The samples were centrifuged at $5000 \mathrm{rpm}$ for $10 \mathrm{~min}$. The supernatants were measured by monitoring the absorbance of each dye in the culture medium at its respective maximum absorption wavelength $(590 \mathrm{~nm}$ for CV, $585 \mathrm{~nm}$ for MV, $617 \mathrm{~nm}$ for MG and $599 \mathrm{~nm}$ for CB) using a UV-Vis spectrophotometer (Libra S12, Biochrom). The dye removal potential was expressed as decolorization efficiency (DE, \%) as follows:

$$
\mathrm{DE}(\%)=\frac{\text { initial absorbance }- \text { observed absorbance }}{\text { initial absorbance }} \times 100 .
$$

\section{Analysis of decolorizing mechanism Analysis of biomass absorption and enzymolysis contributions on the decolorization of TPM dyes}

TPM dyes solution (50 mg/L) was mixed with fungal biomass $(4 \mathrm{~g})$ under shaking $(150 \mathrm{rpm})$ conditions at $30{ }^{\circ} \mathrm{C}$ conditions at 30 fungal biomass decolorization rate as in Sect. 2.4. Control experiments with the dead biomass which were sterilized at $121{ }^{\circ} \mathrm{C}$ for $30 \mathrm{~min}$ were also be carried out (Ting et al. 2016; Wang et al. 2017).

\section{UV-vis spectra of dye solution}

UV-vis spectral analysis was performed to determine the possible occurrence of dyes removal with fungal strains treatment, by comparing the change in peaks of dye samples at initial stage of experiment and post-treatment (from Sect. 2.5.1). Absorption peaks for each TPM dye were detected by means of UV-vis $\left(\mathrm{TECAN}^{\circledR}\right.$, Infinite M 200 plate reader) at wavelengths $400-800 \mathrm{~nm}$. Spectra peaks were plotted and compared (Kalpana et al. 2012).

\section{Fourier transform infrared of fungi}

FTIR analysis was performed to characterize the functional groups present on the cell wall of live cells and dead cells of fungal biomass. To confirm the existence and responsibility of functional groups on the fungal biomass in biosorption, FTIR spectra of the biomass samples (from Sect. 2.5.1) before and after biosorption were obtained using FT-IR spectrum (Perkin Elmer, USA) conducted in ambient temperature. Data were collected within the mid-infrared region from 4000 to $400 \mathrm{~cm}^{-1}$ (20-scan speed) (Chew and Ting 2016; Munck et al. 2018).

\section{Enzyme assays}

Enzyme activities were estimated spectrophotometrically by using the optimized crude supernatant fractions. The control was prepared by inoculating PDB with 5 mycelium plugs $\left(5 \mathrm{~mm}^{2}\right)$ and incubated with agitation $\left(150 \mathrm{rpm}, 30 \pm 2{ }^{\circ} \mathrm{C}\right)$. Enzyme activity was measured after $24 \mathrm{~h}$ in the treatment and control groups. MnP activity was determined by oxidation of $\mathrm{MnSO}_{4}$ (Asgher et al. 2016). The reaction mixture had a final volume of $2 \mathrm{~mL}$ containing $0.05 \mathrm{M}$ of $\mathrm{MnSO}_{4}$ in $0.1 \mathrm{M}$ sodium acetate buffer $\mathrm{pH} 5$ and supernatant (enzyme sample). The reaction was initiated by addition of hydrogen peroxide at a final concentration of $0.5 \mathrm{mM}$. The mixture was incubated for $10 \mathrm{~min}$ at $25{ }^{\circ} \mathrm{C}$ and the increase in absorbance was measured at $470 \mathrm{~nm}$. The LiP activity was measured by the oxidation of veratryl alcohol to veratryl aldehyde. The final $3.0 \mathrm{~mL}$ of reaction volume contained $0.2 \mathrm{M}$ tartaric acid, $10 \mathrm{mM}$ veratryl alcohol, $2 \mathrm{M} \mathrm{H}_{2} \mathrm{O}_{2}$ and supernatant (enzyme sample). Controls were maintained without addition of $\mathrm{H}_{2} \mathrm{O}_{2}$. The samples were incubated at $25{ }^{\circ} \mathrm{C}$ for $15 \mathrm{~min}$ and increase in absorbance was monitored spectrophotometrically at $310 \mathrm{~nm}$ (Takamiya et al. 2008). The Lac assay was performed by detecting oxidation of 2,2'-azinobis (3-ethylbenzthiazoline)-6-sulfonate (ABTS) in control and treated samples via colorimetric change at $420 \mathrm{~nm}$ (Chen and Ting 2015a, b). The reaction mixture contained $5 \mathrm{mM}$ ABTS in $0.1 \mathrm{M}$ sodium acetate buffer (pH 5.0) and supernatant (enzyme sample). One enzyme unit was defined as the amount of enzyme required to catalyze the conversion of 1 micromole of substrate per min at $25^{\circ} \mathrm{C}$.

\section{Phytotoxicity studies}

Toxicity of TPM dyes before and after treatment was inspected against two commonly cultivated crops, which are Vigna radiata and Zea mays plant seeds. About $5 \mathrm{~mL}$ each of $100 \mathrm{mg} / \mathrm{L}$ TPM dyes solution with and without fungal treatment (biomass $2 \mathrm{~g}, 150 \mathrm{rpm}, 30 \pm 2{ }^{\circ} \mathrm{C}$ ) was used for the assay. Ten seeds of each plant were sowed in 
the Petri plates and with sterile distilled water as a control at $28{ }^{\circ} \mathrm{C}$ culture for 5 days (Kalpana et al. 2012). The phytotoxicity was evaluated on the basis of their percentage germination (\%) and the shoot length (plumule) and root length (radicle) measured after the incubation for 5 days.

\section{Statistical analysis}

All data in this paper are the mean value $( \pm S D)$ of three independent replicates. SPSS 19.0 software was used for statistical analysis. Statistically significant differences among the experimental treatments were analyzed using one-way analysis of variance (ANOVA) followed by Duncan's test at 0.05 probability level.

\section{Results and discussion}

\section{Screening of TPM dyes decolorization strain}

In this study, the 14 strains of endophytic fungi were isolated from the roots of Sinosenecio oldhamianus. The decolorization capability of these endophytic isolate were assessed on MBM plates with 4 types of TPM dyes (CV, MV, MG and $\mathrm{CB}$ ). The tested fungal strains on solid medium exhibited a different potential of TPM dyes decolorization. It is worth noting that only one endophyte, isolate SWUSI4, was able to decolorize all four different TPM dyes and also demonstrated the highest decolorization potential (Additional file 1: Table S1 and Fig. S1). This result conforms with most observations (Jasinska et al. 2012; Yang et al. 2016; Marcharchand and Ting 2017), suggesting that different fungi had different dye decolorization abilities. Simultaneously, the potential of decolorization is related to the adaptability and activity of the selected strains. Obviously, our results indicated that strain SWUSI4 had the capability to decolorize all tested four TPM dyes on solid culture (Additional file 1: Table S1 and Fig. S1). Generally, strains isolated from contaminated areas have been reported to have a strong tolerance and potential for remediation to contaminants (Yang et al. 2009; Almeida and Corso 2018). This study is also the first to report the effectiveness of endophytic fungus from the dye-contaminated Sinosenecio oldhamianus, and its potential in decolorizing TPM dyes. Hence, according to the above mentioned, isolate SWUSI4 was selected for further taxonomical identification as well as more detailed decolorization study.

\section{Identification of isolate SWUSI4}

Morphologically, isolate SWUSI4 produces white fastgrowing colonies with a diameter of $8.34 \mathrm{~cm}( \pm 0.26)$ after 5 days of growth on PDA at a temperature of $28^{\circ} \mathrm{C}$, aerial mycelium abundant, woolly, at first white but later becoming yellowish, reverse white (Additional file 1: Fig. S2A, B). Advancing hyphae dichotomously branched, $4.54 \mu \mathrm{m}( \pm 1.76)$ diameter; and air-borne hyphae dividing into one-celled arthroconidia which remain cylindrical or become ellipsoidal or slightly barrel-shaped, 4.08 $( \pm 0.81) \times 6.20( \pm 2.16) \mu \mathrm{m}$ (Additional file 1: Fig. S2C), which is consistent with the morphological description of B. adusta R59 in the published literature (KornillowiczKowalska et al. 2006). For isolate SWUSI4, the 5.8SrDNA gene sequence was determined and classified in the genus Bjerkandera sp. on the basis of neighbor-joining analysis compared to other similar fungi stains (Fig. 1). This identity was provided on the basis of the nucleotide sequence having a $99 \%$ homology ( $E$ value of $0.0 ; 99 \%$ query coverage) with that of $B$. adusta strain MJ01 deposited in GenBank (accession number HQ327995.1) and B. adusta strain SM27 deposited in GenBank (accession number KU055647.1). Based on molecular taxonomy investigation of the strain SWUSI4, this fungus was identified as $B$. adusta. And the nucleotides sequences were submitted to GenBank and provided a GenBank accession number MN640911.

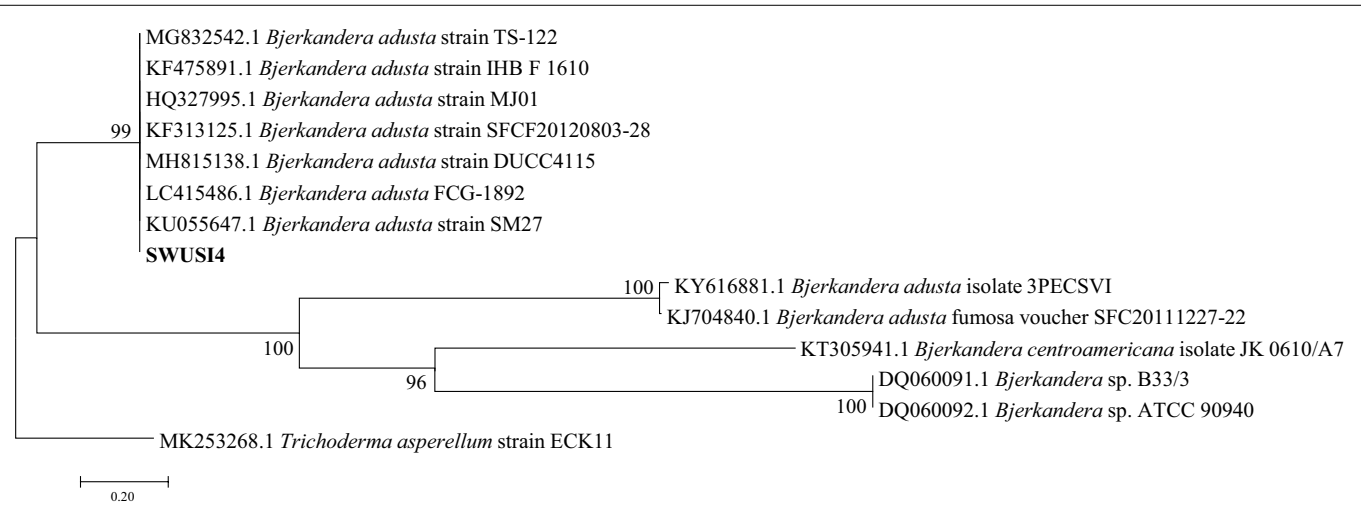

Fig. 1 Neighbor-joining tree based on ITS rDNA sequence of the fungus SWUSI4 and its closest ITS rDNA matches in the GenBank 


\section{Dye decolorization activities of B. adusta SWUSI4} in different conditions

\section{Effects of biomass on dye removal}

The effect of biomass dosage was evaluated at the concentration of $100 \mathrm{mg} / \mathrm{L}(100 \mathrm{~mL})$ at $30{ }^{\circ} \mathrm{C}$ for 14 days. As revealed in Fig. 2a, application of $4 \mathrm{~g}$ of biomass was sufficient to achieve the decolorization efficiency (DE \%) for CV (85\%) and MG (95\%), while CB and MV required $6 \mathrm{~g}$ to achieve maximum DE $89 \%$ and $92 \%$, respectively. In terms of $\mathrm{CV}$ and MG, the maximum DE was observed when the biomass dosage was $6 \mathrm{~g}$, but there were no conspicuous differences between biomass dosage of $6 \mathrm{~g}$ and $4 \mathrm{~g}$ (Fig. 2a). The benefit of using more biomass has also been reported in other studies (Kaushik and Malik et al. 2009; Wang et al. 2017; Bankole et al. 2018; Almeida and Corso 2018); ; ; , which primarily attributed to having more binding sites and enzymes give rise to biosorption and biodegradation, respectively.

In this study, TPM dyes were effectively decolorized by endophytic fungus (isolate SWUSI4) under nonnutritive conditions. Interestingly, successful decolorization TPM dyes by isolate SWUSI4 was similar to other environmental isolates, such as Trichoderma asperellum and Penicillium simplicissimum, revealing the nature of fungi as dye degraders (Chen and Ting 2015a, b; Marcharchand et al. 2017). Therefore, we further compared the decolorization rate of endophytic B. adusta SWUSI4 with other strains reported previously. For example, Marcharchand and Ting (2017) have reported that CV, MV, MG and CB (100 mg/L) were decolorized up to 11, 67, 76 and $57 \%$, respectively, by Trichoderma asperellum within 336 h (14 days). Another non-white rot fungi Penicillium simplicissimum showed 76, 79, 54 and 64\% decolorization of CV, MV, MG and CB (100 mg/L) within $336 \mathrm{~h}$ (14 days), respectively. However, endophytic fungus SWUSI4 demonstrated strong decolorization efficiency for CV, MV, MG and CB (100 mg/L) within 14 days were $72 \%, 81 \%, 91 \%$ and $70 \%$, respectively. By contrast, endophytic strain SWUSI4 decolorization efficiency to CV, MV, MG and CB is greater than above-mentioned control strains.

In general, decolorization efficiency rose with the increase of biomass dosage at a certain dye concentration. However, in the present study, when biomass ranged from 6 to $8 \mathrm{~g}$, DE value was significantly down to $84-74 \%$ (CV), 92-83\% (MV), 96-82\% (MG) and 89-77\% (CB), respectively (Fig. 2A). This result showed that the higher biomass (6 or $8 \mathrm{~g}$ ) suppressed decolorization efficiency, the reason of which was caused by the dye initial concentration in the culture medium rather than the dosage of inoculum (Chen et al. 2015a). Hence, the results obtained from this investigation demonstrated that biomass of endophytic fungus not only can decolorize TPM dyes, but also suitable biomass could be efficiently employed as a low-cost and eco-friendly biosorbent for TPM dye removal.

\section{Influence of initial dye concentrations on decolorization}

Effect of initial dye concentration on the decolorization ability of SWUSI4 was studied by adding the fungal biomass $(2 \mathrm{~g})$ to $\mathrm{CV}, \mathrm{MV}, \mathrm{MG}$ and $\mathrm{CB}$ solution $(100 \mathrm{~mL})$ with different initial concentrations $(50,100$, 150, 200 and $250 \mathrm{mg} / \mathrm{L}$, respectively). Decolorization efficiency (DE) was calculated after 14 days at $30{ }^{\circ} \mathrm{C}$.

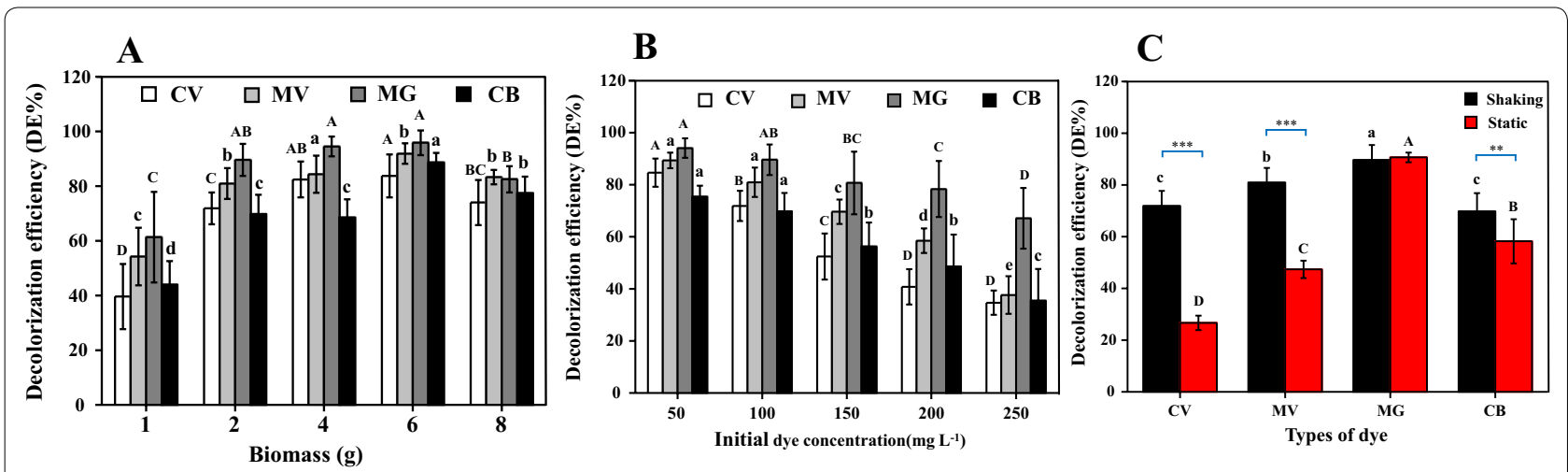

Fig. 2 Optimum decolorization conditions for isolate SWUSI4. A: Influence of biomass (1, 2, 4, 6 and $8 \mathrm{~g}$, respectively) of SWUSI4 on the decolorization activities of CV, MV, MG and CB. B: Influence of initial dye concentrations (50, 100, 150, 200 and $250 \mathrm{mg} \mathrm{L}^{-1}$, respectively) of SWUSI4 on the decolorization activities of CV, MV, MG and CB. C: Influence of static and shaking conditions of SWUSI4 on the decolorization activities of CV, MV, MG and CB. Note: Means with the same letters and captions are not significantly different at honestly significant difference (HSD (0.05)). Mean comparisons are made for means with the same fonts. For example, means designated " $A$ " compared to another mean with " $A$ " Duncan grouping is not significantly different, while " $A$ " compared to " $B$ " and " $C$ " is significantly different. Similarly, means with "a" are not significantly different compared to "a" but are for " $b$ " and " $c$ ". "**" indicates significant difference based on T-test (** $p<0.01$, *** $p<0.001)$. Bars indicate standard deviation of mean ( $\pm \mathrm{SD})$ 
For four tested TPM dyes, it was evident that the DE declined when initial dye concentration increased. At the dye concentration of $50 \mathrm{mg} / \mathrm{L}$, SWUSI4 allowed 85, 90, 94 and $80 \%$ DE of CV, MV, MG and CB, respectively (Fig. 2b); whereas, when the initial dye concentration was $250 \mathrm{mg} / \mathrm{L}$, DE reached $34 \%, 37 \%, 67 \%$ and $35 \%$ for CV, MV, MG and CB, respectively (Fig. 2b). Similar results have also been reported by Lin et al. (2010), who found that the decolorization efficiency of Mucoromycotina sp. declined with increasing initial dye concentrations. The implications of high initial dye concentrations agreed with most investigations (Chen and Ting 2015; Wang et al. 2017; Almeida and Corso 2018), thus suggesting that the toxicity of dye could be more pronounced at higher dye concentrations which may suppress the microbial growth. In order to improve the decolorization ability, $50 \mathrm{mg} / \mathrm{L}$ TPM dyes solution was chosen as the optimum dye concentration.

\section{Effect of shaking and stationary conditions}

To determine the effects of static and shaking conditions on decolorization, this effect was studied under two different conditions $(0 \mathrm{rpm}$ and $150 \mathrm{rpm}$, respectively), by treating $100 \mathrm{ml}$ of dye solutions with fungal biomass $2.0 \mathrm{~g}$, initial dye concentrations $100 \mathrm{mg} / \mathrm{L}$ with other experimental conditions remaining constant. Comparatively, SWUSI4 in shaking condition was more effective in decolorizing TPM dyes than in static condition (Fig. 2c). Among them, the DE on CV, MV and CB were significantly higher in shaking condition with means $72 \%, 81 \%$ and $70 \%$ as compared to $27 \%, 47 \%$ and $58 \%$ in static condition, respectively (Fig. 2c). Nevertheless, the DE of MG dye under shaking condition is similar to static condition (90\% vs. 91\%) (Fig. 2c). According to the authors, the higher decolorization under shaking condition than in static condition is primarily dependent on the oxidative reactions by key enzymes such as LiP and Mnp (Shedbalkar et al. 2008; Zhuo et al. 2011). Besides, it has been reported that the shaking condition was better for faster and complete adsorption and decolorization of $\mathrm{MV}$ and $\mathrm{CV}$ by Coriolopsis sp., as well as CB by Penicillium simplicissimum KP713758 or Coriolopsis sp. as compared to the static conditions (Chen and Ting 2015). However, in another case, the process of decolorization does not require oxygen and most possibly involved reductive reactions by a different set of reductases. We assumed that the discrepancy of decolorization between static and shaking incubation conditions seemed to be related to the fungal species. All in all, our results demonstrated that decolorization could be more efficient under shaking incubation conditions.

\section{Analysis of decolorizing mechanism \\ Biomass absorption or adsorption and enzymolysis contributions of B. adusta on the removal of TPM dyes}

To evaluate the effect of biodegradation and biosorption, the decolorization of TPM dyes was performed separately by live cells and dead cells under optimized conditions. As shown in Fig. 3, TPM dyes solution $(50 \mathrm{mg} / \mathrm{L})$ was mixed with fungal biomass $(4 \mathrm{~g})$ under shaking $(150 \mathrm{rpm})$ conditions at $30{ }^{\circ} \mathrm{C}$ for 7 days, the decolorization efficiency of live cells for MG, MV, CB and CV was $97 \%, 94 \%, 94 \%$ and $92 \%$, respectively. By contrast, dead cells showed decolorization capacities of $72 \%, 71 \%, 64 \%$ and $53 \%$ for MG, MV, CB and CV, respectively. Furthermore, the decolorization process by live cells of $B$. adusta SWUSI4 was rapid compared to dead cells. Live cells achieved DE for CV, MV, MG and CB allowed rapid decolorization within $24 \mathrm{~h}$ (91\%, 94\%, 96\% and 93\%, respectively). By contrast, dead cells achieved DE for CV, MV, MG and CB allowed 45\%,63\%, 68\% and 55\%, respectively, decolorization within $24 \mathrm{~h}$ (Additional file 1: Fig. S3). In general, the higher DE by live cells as opposed to dead cells has been reported in other studies as well Ting et al. (2016); Przystas et al. (2018); Chen et al. (2019a, b, c). This has been primarily attributed to the biodegradation of live cells because they can produce lignin enzymes, such as MnP, LiP and Lac (Srinivasan and Viraraghavan 2010; Marcharchand and Ting 2017; Munck et al. 2018).

It is well known that decolorization occurred by adsorption of the fungal mycelium firstly, and then followed by enzymes of the live cells (Parshetti et al. 2011).

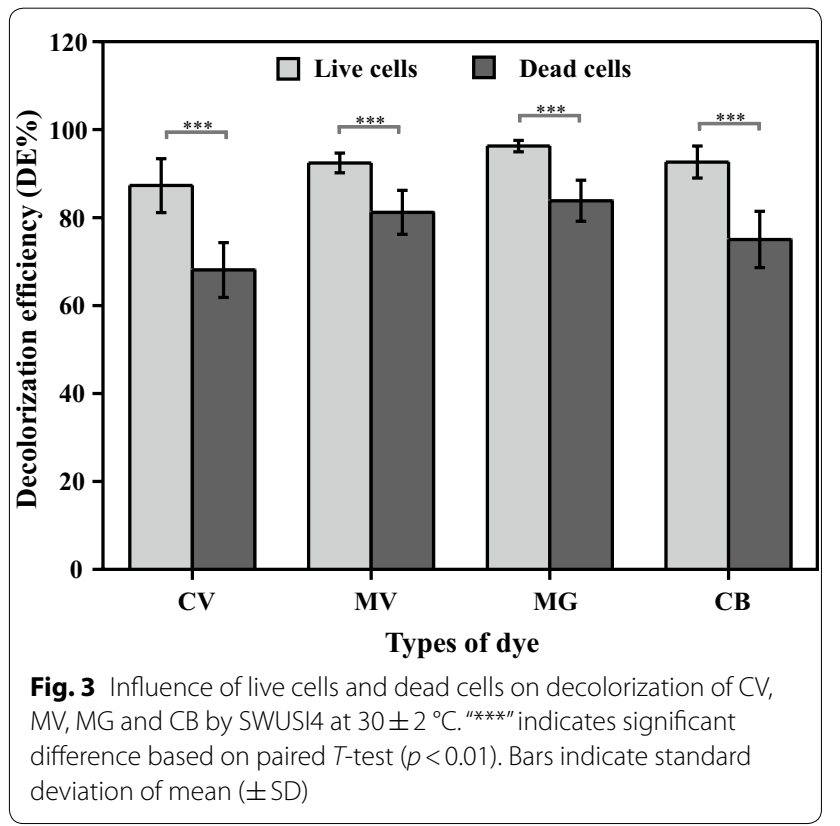


However, the decolorization merely depended on the absorption once the mycelia were dead (Wang et al. 2017). On the other hand, according to Casas et al. (2009), the occurrence of biosorption can be concluded by the dye-colored fungal cells after decolorization. In our study, after the decolorization the color of dead cells was same as corresponding TPM dyes, respectively, while the dye solution turned lighter after decolorization by live cells (Additional file 1: Fig. S4). This result indicated that live cells may degrade dyes to a certain extent by enzymes. Thus, absorption presumably played a major role in the decolorization as well as degradation also had a certain role when using live cells.

\section{UV-Vis analysis}

As shown in Fig. 4, for both treatments with live and dead cells of B. adusta SWUSI4 for 7 days, these absorbance peaks were obviously observed to reduce or disappear after decolorization. According to the reports (Ting et al. 2016; Ortiz-Monsalve et al. 2019; Munck et al. 2018), the disappearance or reduction of peaks in dyes can be attributed to the enzymatic biodegradation or biosorption of biomass. In our results, the complete dissolution of maximum absorption peaks were clearly observed for CB and MG treated with live cells of B. adusta (Fig. 4a, c). For $\mathrm{CV}$ and MV treated with live cells, the corresponding maximum absorption peak dramatically decreased in intensity after application with SWUSI4 (Fig. 4b, d). For $\mathrm{CV}, \mathrm{MV}, \mathrm{MG}$ and $\mathrm{CB}$ treated with dead cells of $B$. adusta, the maximum absorption peaks remained detectable after 7 days (Fig. 4e-h). Furthermore, the decrease degree of the maximum absorption peaks seems to be proportional to the decolorization percentage of their corresponding dyes detected, especially from $0-1$ day irrespective of whether live or dead cells of $B$. adusta SWUSI4 were used. Previously, it has been reported that a decrease in absorbance peaks and appearances of a new peak reflects the removal of dye via biodegradation leading to biodecolorization, while dead cells destroyed the absorption peak via biosorption (Asad et al. 2007; Chen and Ting 2015). Association with decolorization percentage and UV-vis analysis, it can be stated that the decolorization of four tested TPM dyes carried out by live cells of isolate SWUSI4 were related to both biodegradation and biosorption, while dead cells only via biosorption.

\section{FTIR analyses}

In the present study, the FTIR analysis revealed there were no significant differences in the number of functional groups present on the cell wall of live cells and dead cell forms of SWUSI4. These primary functional groups include hydroxyl, amino, phosphoryl alkane, and ester-lipids groups (Tables 1 and 2). For live cells, the treatments with $\mathrm{CV}, \mathrm{MV}, \mathrm{MG}$ and $\mathrm{CB}$ caused peaks to shift at $3394 \mathrm{~cm}^{-1}$ (representing $\mathrm{O}-\mathrm{H}$ and $\mathrm{N}-\mathrm{H}$ groups), $2368 \mathrm{~cm}^{-1}$ ( $\mathrm{C}=\mathrm{C}$ stretching of ester), $1654 \mathrm{~cm}^{-1}(\mathrm{C}=\mathrm{O}$ stretching and $\mathrm{N}-\mathrm{H}$ deformation of amide $\mathrm{I}$ band), $1076 \mathrm{~cm}^{-1}$ (denoting $\mathrm{C}-\mathrm{C}, \mathrm{C}=\mathrm{C}, \mathrm{C}-\mathrm{O}-\mathrm{C}$ and $\mathrm{C}-\mathrm{O}-\mathrm{P}$ groups of polysaccharides) and $528 \mathrm{~cm}^{-1}$ (nitro compounds and disulphide groups) (Table 1). Interactions between phosphoryl group and TPM dyes may have occurred according to the shift of a peak at $1076 \mathrm{~cm}^{-1}$ and disappearance of a peak at $1149 \mathrm{~cm}^{-1}$. Furthermore, another peak at $1251 \mathrm{~cm}^{-1}$ (also denoting the phosphate
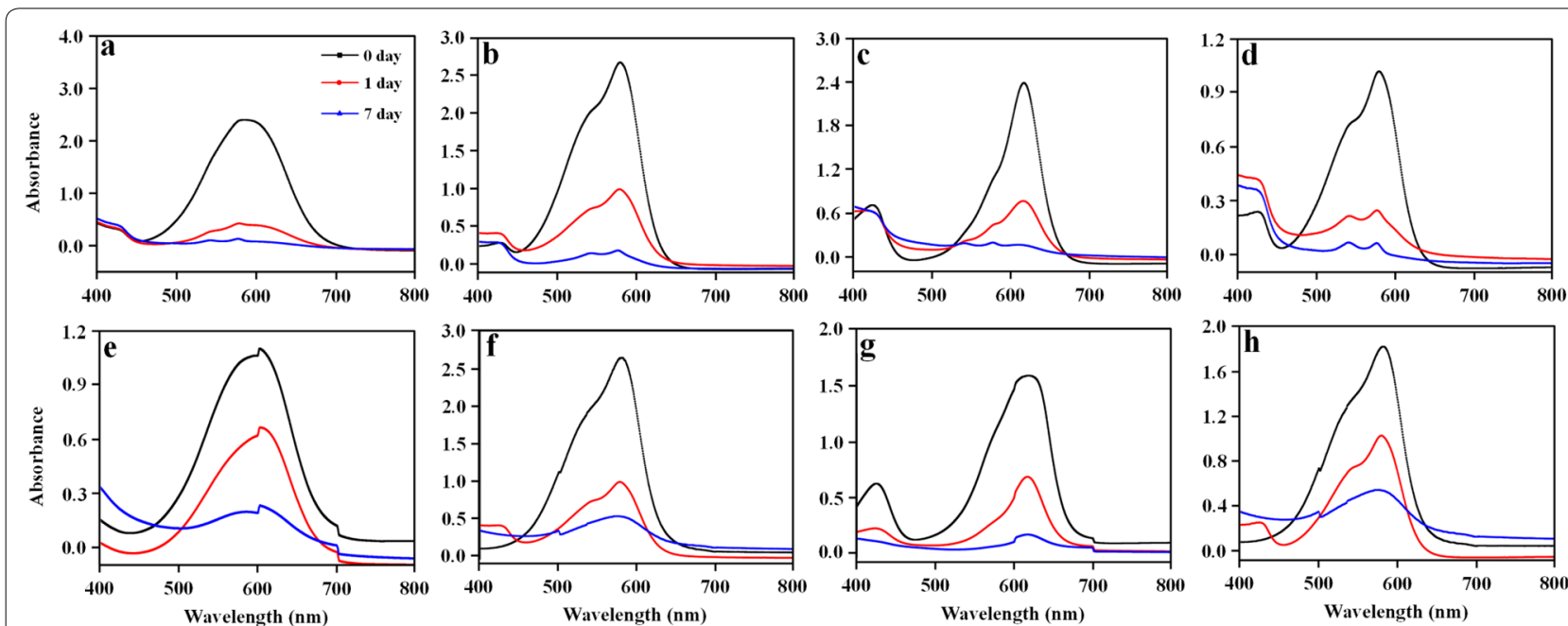

Fig. 4 The UV-vis spectrum analysis derived from a CB + live cells, $\mathbf{b} C V+$ live cells, $\mathbf{c} M G+$ live cells, $\mathbf{d} M V+$ live cells, e CB + dead cells, $\mathbf{f} C V+$ dead cells, $\mathbf{g}$ MG + dead cells, $\mathbf{h}$ MV + dead cells. Analysis was conducted at the start of the experiment (day 0 ) and at day 1, day 7 post-treatment, respectively 
Table 1 Exemplary FTIR band positions (cm-1) of live cells of isolate SWUSI4 before and after treatment with CV, MV, MG and CB

\begin{tabular}{llllll}
\hline $\begin{array}{l}\text { Untreated } \\
\text { live cells }\end{array}$ & CV-loaded cells & MV-loaded cells & MG-loaded cells & CB-loaded cells & Suggested assignment \\
\hline 3394 & 3444 & 3439 & 3425 & 3442 & \\
2926 & 2924 & 2924 & 2924 & 2926 & O-H and N-H stretching vibrations \\
2368 & 2378 & 2378 & 2378 & 2380 & C-H asymmetric stretching \\
2339 & 2341 & 2341 & 2341 & 2341 & C=C stretching of ester \\
& 1741 & 1741 & 1741 & 1741 & C=C stretching of ester \\
1654 & 1645 & 1645 & 1645 & 1645 & C=O stretching of ester \\
1562 & 1560 & 1560 & 1560 & 1560 & C=O stretching and N-H deformation (amide I region) \\
1456 & 1456 & 1456 & 1456 & 1456 & N-H bending in amide II and C-N stretching in -CO-NH- \\
1406 & 1413 & 1413 & 1415 & 1415 & C-N stretching and N-H bending of amide III \\
1251 & & 1261 & 1251 & C-N stretching and N-H bending of amide III \\
1149 & 1251 & & & Phosphate group \\
1076 & 1066 & 1068 & 1070 & 1066 & Phosphate group \\
1033 & 1022 & 1028 & & & Phosphate group/C-C, C=C, C-O-C, C-O-P of saccharides \\
& 636 & 636 & 636 & C-C, C=C, C-O-C, C-O-P of saccharides \\
528 & 524 & 543 & 522 & 522 & Aromatic C-H stretching \\
426 & 418 & 418 & 422 & Nitro compounds and disulfide groups \\
\hline
\end{tabular}

Table 2 Exemplary FTIR band positions (cm-1) of dead cells of isolate SWUSI4 before and after treatment with CV, MV, MG and CB

\begin{tabular}{llllll}
\hline $\begin{array}{l}\text { Untreated } \\
\text { dead cells }\end{array}$ & CV-loaded cells & MV-loaded cells & MG-loaded cells & CB-loaded cells & Suggested assignment \\
\hline 3415 & 3427 & 3423 & 3439 & 3423 & O-H and N-H stretching vibrations \\
2926 & 2924 & 2924 & 2924 & 2922 & C-H asymmetric stretching \\
& & & 2857 & C-H asymmetric stretching \\
2368 & 2372 & 2378 & 2378 & 2378 & C=C stretching of ester \\
2339 & 2339 & 2341 & 2341 & 2341 & C=C stretching of ester \\
& 1741 & 1743 & 1741 & 1741 & C=O stretching of ester \\
1645 & 1645 & 1645 & 1645 & 1645 & C=O stretching and N-H deformation (amide I region) \\
1560 & 1560 & 1560 & 1560 & 1560 & N-H bending in amide II and C-N stretching in -CO-NH- \\
1456 & 1456 & 1458 & 1458 & 1456 & C-N stretching and N-H bending of amide III \\
1404 & 1415 & 1413 & 1413 & 1415 & C-N stretching and N-H bending of amide III \\
1327 & 1344 & 1342 & 1342 & 1344 & Amide III \\
1078 & 1068 & 1066 & 1070 & & Amide III \\
1033 & 1022 & 1022 & 1024 & 1043 & Phosphate group/C-C, C=C, C-O-C, C-O-P of saccharides \\
927 & & 927 & & Phosphate group/C-C, C=C, C-O-C, C-O-P of saccharides \\
775 & & & & Phosphate (PO4) in polysaccharides \\
428 & 420 & 420 & 422 & Aromatic C-H stretching/N-O stretching of alcohol \\
& & & 422 & Nitro compounds and disulfide groups
\end{tabular}

group) was masked after $\mathrm{CV}$ treatment and shifted to $1261 \mathrm{~cm}^{-1}$ after MG treatment although no changes in this peak was not observed for CB and MV-treated live cells. In addition, new peak at $1741 \mathrm{~cm}^{-1}$ was detected $(\mathrm{C}=\mathrm{O}$ group $)$ in all dye-treated live cells. On the contrary, the involvement of $\mathrm{C}-\mathrm{H}$ stretching vibrations at
2926 and $2339 \mathrm{~cm}^{-1}$, and amide III group at $1456 \mathrm{~cm}^{-1}$ in dye adsorption were not prominent (Table 1). On the other hand, dye-treated dead cells displayed similar changes in vibrational frequencies as for live cells, though with was more new peaks appearing (Table 2). The peaks at 3415, 2368, 1404 and $1033 \mathrm{~cm}^{-1}$ shifted 
after exposure to the four dyes. In addition, a weak shift from 2926 to $2924 \mathrm{~cm}^{-1}$ (C-H asymmetric stretching) was observed for CV, MV and MG-treated dead cells. All four dyes caused the disappearance of two peaks at 1327 and $775 \mathrm{~cm}^{-1}$, and the emergence of a new peak at $1741 \mathrm{~cm}^{-1}(\mathrm{C}=\mathrm{O}$ stretching of ester $)$. Further, new peak at $2857 \mathrm{~cm}^{-1}$ was detected $(\mathrm{C}-\mathrm{H}$ stretching) in CB-treated dead cells, whereas peaks at $927 \mathrm{~cm}^{-1}$ were masked in all treated dead cells but MG. The MV and MG treatments result in the emergence of a new peak at $1342 \mathrm{~cm}^{-1}$ (Amide III), and shifting of existing peaks at 1456 and $1404 \mathrm{~cm}^{-1}(\mathrm{C}-\mathrm{N}$ stretching) (Table 2). Additionally, the $\mathrm{CV}$ and $\mathrm{CB}$ treatments also led to the emergence of a new peak at $1344 \mathrm{~cm}^{-1}$, and shifting of existing peaks at $1404 \mathrm{~cm}^{-1}$.

The changes in vibrational frequencies recorded via FTIR analyses on the chemical surface composition of dye-treated $B$. adusta confirmed the involvement of biosorption in dye removal. For example, Yang et al. (2011) showed that the biosorption of Acid Blue 25 by dead (autoclaved) Penicillium YW 01 involved amine, amide and carboxyl groups. Another fungus Aspergillus fumigatus, removal of Acid Violet 49 by dead (through freezing) was attributed to amino, carboxyl, phosphate, and sulfonyl groups (Chaudhry et al. 2014). Similarly, Chen et al. $(2019 a-c)$ also reported that removal of TPM dyes by live cells and dead cells (autoclaving) of Penicillium simplicissimum involved amino, hydroxyl, phosphoryl, nitro groups, etc. This is evidence that dead cells (autoclaving) did not have severe implications on the functional groups on the cell wall, as most of the major functional groups were detected. They may also be typical functional groups on the cell walls of a variety of fungi (Marcharchand and Ting 2017; Chew and Ting 2016). Additionally, the number of functional groups does not necessarily correlate with their potential in dye removal since the number of functional groups is almost the same present on the cell wall of live cells and dead cell forms of SWUSI4. This further explained that the higher decolorization efficiency of live cells may be attributed to the role of enzymes secreted. However, positively charged and negatively charged groups are important to attract both basic and acidic dyes through electrostatic attraction which is the basis of the biosorption mechanism of dye removal (Marcharchand and Ting 2017). Therefore, the involvement of chemical groups of SWUSI4 in the removal of TPM dyes substantiated biosorption as part of the dye removal mechanisms.

\section{Enzymatic activities}

In order to get additional insight into the enzymolysis contributions of SWUSI4 on the removal of dye, the enzyme activities of Lac, MnP and LiP were monitored after $24 \mathrm{~h}$ in the treatment and control groups. As shown in Table 3, our results demonstrated that SWUSI4 produced more LiP and $\mathrm{MnP}$ as their levels were significantly induced compared to controls in the presence of TPM dyes. Different from LiP and MnP, Lac activities demonstrated to be significantly lower than in the control. The levels of MnP and Lip were significantly higher in all TPM dyes compared to the level of Lac levels, indicating SWUSI4 may rely more on LiP and MnP oxidase for biodegradation. Additionally, $\mathrm{MnP}$ and LiP activity in MG was higher than that in MV, indicating that the relative contribution of each enzyme to dye decolorization is different for SWUSI4.

Generally, the relative contributions of LiP, MnP and Lac to the decolorization of dyes may be different for each fungus (Srinivasan and Viraraghavan 2010; Wang et al. 2017). Previously, Phanerochaete chrysosporium have been reported as Lip producers able to decolorize CV (Bumpus and Brock 1988), Irpex lacteus as Mnp producers able to decolorize MG (Yang et al. 2016; Duan et al. 2018) and Pleurotus ostreatus as Lac producers able to decolorize MG and CV (Morales-Álvarez et al. 2018). Besides fungi, contribution of these enzymes in biodegradation process highly depends on type of dyes (Al Farraj et al. 2019). For instance, Chen and Ting (2019) revealed

Table 3 Activities of laccase (Lac), lignin peroxidase (LiP) and manganese peroxidase (MnP) assayed from isolate SWUSI4 cultures exposed to TPM dyes compared to control (in potato dextrose broth only)

\begin{tabular}{|c|c|c|c|c|c|}
\hline \multirow[t]{2}{*}{ Enzyme } & \multicolumn{5}{|c|}{ Enzymatic activities derived from } \\
\hline & PDB & CV & MV & MG & CB \\
\hline $\operatorname{Lac}^{\mathrm{a}}$ & $0.1035 \pm 0.0012$ & $0.0200 \pm 0.0002^{*}$ & $0.0185 \pm 0.0029^{*}$ & $0.0235 \pm 0.0010^{*}$ & $0.0036 \pm 0.0002^{*}$ \\
\hline Lip $^{a}$ & $0.0067 \pm 0.0019$ & $0.0144 \pm 0.0022$ & $0.0579 \pm 0.0403^{*}$ & $0.0815 \pm 0.0268^{*}$ & $0.0339 \pm 0.0018^{*}$ \\
\hline$M n P^{a}$ & $0.0459 \pm 0.0072$ & $0.1527 \pm 0.0496^{*}$ & $0.1796 \pm 0.0543^{*}$ & $0.2208 \pm 0.0106^{*}$ & $0.1875 \pm 0.0194^{*}$ \\
\hline
\end{tabular}

Data presented with standard deviation of mean $( \pm S D)$ are mean of triplicates

Asterisk "*indicates significant difference in enzymatic levels from those in potato dextrose broth based on $T$-test $(p<0.05)$

a Units $\mathrm{min}^{-1} \mathrm{ml}^{-1}$ 
that the enzyme activities of manganese peroxidase were significantly enhanced in response to MG, whereas only tyrosinase activities were higher when inoculated into MV and CB. Similarly, in Penicillium simplicissimum (isolate 10), higher levels of LiP were detected in cultures supplemented with MV and CV (Chen and Ting 2015). Therefore, for this reason, we studied the relative contributions of LiP, MnP and Lac produced by endophytic isolate SWUSI4 to degraded TPM dyes. For this reason, we studied the enzymes produced by endophytic isolate SWUSI4. Overall, the strain SWUSI4 showed that the activity of $\mathrm{MnP}$ and Lip are higher than Lac in this study. As such, MnP presumably played an important role in the decolorization as well as Lip also had a certain role and therefore can regulate biodegradation of TPM dyes to some extent.

\section{Phytotoxicity test}

Parshetti (2010) reported that plants belong to the group of sensitive indicators of remediation. Therefore, two common crops Vigna radiata and Zea mays were tested for toxicity in this study. The germination rate, shoot and root length of germinated seeds were observed and presented in Table 4. The seed germination rate in Vigna radiata was not affected by CB (100\%), but was inhabited by CV, MV and MG (85, 90 and $80 \%$, respectively). Similarly, the inhibition of CV, $\mathrm{MV}, \mathrm{MG}$ and $\mathrm{CB}$ on germination of Zea mays was 70, 80,60 and $90 \%$, respectively, compared with sterile distilled water (Table 4). Meanwhile, seed germination of Vigna radiata was enhanced and improved by $100 \%$ for all the four tested TPM dyes compared to the untreated dye sample. Similarly, seed germination of Zea mays was also increased by $93,95,90$ and $100 \%$ for CV, MV, MG and CB of isolate SWUSI4 treatment, respectively.
On the other hand, compared to untreated TPM dyes, the enhanced and significant growth of the shoot and root of Vigna radiata and Zea mays suggests reduced toxicity after treatment $(p<0.05)$ (Table 4$)$. In addition, in the case of plants, Vigna radiata was less affected than Zea mays, suggesting that Zea mays might have higher sensitivity towards dye toxicity compared to Vigna radiata. On the whole, the result suggests that the all four tested TPM dyes were toxic to both plants, while the metabolites formed after treatments were less toxic or nontoxic, which signifies the detoxification of TPM dyes by B. adusta SWUSI4 (Chen et al. 2019a, b, c).

\section{Conclusions}

This study is the first to report the effectiveness of endophytic fungi isolated from the Sinosenecio oldhamianus to decolorize TPM dyes (CV, MV, MG, and CB). Among them, the isolate SWUSI4 (B. adusta) had the best decolorization ability for four tested TPM dyes. The decolorization efficiency of SWUSI4 was influenced by initial dye concentrations, fungal biomass, and shaking. The better biosorption of TPM dyes by isolate SWUSI4 has been majorly attributed to the predominance of hydroxyl, amino, phosphoryl, alkane, etc., groups on the surface of the cell wall of SWUSI4. Biodegradation played an important role in dye decolorization, which resulted in reduced absorbance peaks for dyes, $\mathrm{LiP}$ and $\mathrm{MnP}$ levels were significantly induced, and degraded products were also found to be less toxic compared with before degradation. Hence, this work indicated that B. adusta SWUSI4 has potential application prospects for the biodecolorization and detoxification of TPM dyes.

Table. 4 Results of phytotoxicity tests of TPM dye and its metabolites produced by the fungus SWUSI4 on Vigna radiate and Zea may

\begin{tabular}{|c|c|c|c|c|c|c|c|c|c|}
\hline \multirow[t]{2}{*}{ Parameters studied } & \multirow{2}{*}{$\begin{array}{l}\text { Control } \\
\text { DW }\end{array}$} & \multicolumn{4}{|l|}{ TPM dyes } & \multicolumn{4}{|c|}{ Biodegraded products } \\
\hline & & CV & MV & MG & CB & Treated CV & Treated MV & Treated MG & Treated CB \\
\hline \multicolumn{10}{|l|}{ Vigna radiata } \\
\hline Germination (\%) & 100 & 85 & 90 & 80 & 100 & 100 & 100 & 100 & 100 \\
\hline Root (cm) & $4.40 \pm 0.26$ & $2.47 \pm 0.15^{* *}$ & $2.30 \pm 0.10^{* *}$ & $1.97 \pm 0.15^{* *}$ & $2.60 \pm 0.10^{* *}$ & $3.70 \pm 0.20^{*}$ & $3.73 \pm 0.61^{*}$ & $3.67 \pm 0.35^{*}$ & $4.90 \pm 0.20^{*}$ \\
\hline Shoot (cm) & $4.93 \pm 0.15$ & $3.27 \pm 0.21^{* *}$ & $3.33 \pm 0.15^{* *}$ & $3.23 \pm 0.15^{* *}$ & $5.00 \pm 0.10$ & $4.53 \pm 0.25^{*}$ & $4.47 \pm 0.06^{*}$ & $4.67 \pm 0.12^{*}$ & $7.90 \pm 0.20^{*}$ \\
\hline \multicolumn{10}{|l|}{ Zea mays } \\
\hline Germination (\%) & 100 & 70 & 80 & 60 & 90 & 93 & 95 & 90 & 100 \\
\hline Root $(\mathrm{cm})$ & $4.72 \pm 0.16$ & $2.22 \pm 0.18^{* *}$ & $2.85 \pm 0.04^{* *}$ & $2.82 \pm 0.02^{* *}$ & $3.21 \pm 0.08^{* *}$ & $4.80 \pm 0.82^{*}$ & $4.44 \pm 0.27^{*}$ & $4.49 \pm 0.20^{*}$ & $7.09 \pm 0.68^{*}$ \\
\hline Shoot $(\mathrm{cm})$ & $3.99 \pm 0.06$ & $2.84 \pm 0.13^{* *}$ & $2.54 \pm 0.24^{* *}$ & $2.64 \pm 0.14^{* *}$ & $3.29 \pm 0.06^{* *}$ & $4.14 \pm 0.33^{*}$ & $3.34 \pm 0.11^{*}$ & $3.49 \pm 0.02^{*}$ & $4.03 \pm 0.15^{*}$ \\
\hline
\end{tabular}

Values of root and shoot lengths are presented as mean of three experiments $\pm S D$

Root and shoot lengths of seeds grown in TPM dyes are significantly different from that of plants grown in sterile distilled water by ** $p<0.01$, Root and shoot lengths of seeds grown in biodegraded products of TPM dyes are significantly different from that of plants grown in TPM dyes by ${ }^{*} p<0.05$ 


\section{Supplementary information}

Supplementary information accompanies this paper at https://doi. org/10.1186/s40643-020-00340-8.

Additional file 1: Additional table and figures.

\section{Abbreviations}

TPM: Triphenylmethane; CV: Crystal violet; MV: Methyl violet; MG: Malachite green; CB: Cotton blue; LiP: Lignin peroxidase; MnP: Manganese peroxidase; Lac: Laccase; PD: Potato dextrose; ITS: Internal transcribed spacers; DNA: Deoxyribonucleic acid; CTAB: Cetyltrimethylammonium bromide; NCBI: National Center for Biotechnology Information; ABTS: 2,2'-Azinobis (3-ethylbenzthiazoline)-6-sulfonate; DE: Decolorization efficiency; FTIR: Fourier transform infrared; UV-vis: Ultraviolet-visible.

\section{Acknowledgements}

This work was financially supported by the Natural Science Foundation of Chongqing (cstc2017jcyjAX0225).

\section{Authors' contributions}

Conceived and designed the experiments: TCG. Performed the experiments: TCG, DQ, SHZ, YJP and JRX. Analyzed the data:TCG, DQ and YJP. Contributed agents/materials/analysis tools: TCG, YJP, DQ, BHY, HCS. Wrote the paper: TCG. All authors read and approved the final manuscript.

\section{Funding}

This work was financially supported by the Natural Science Foundation of Chongqing (cstc2017jcyjAX0225).

\section{Data availability statements}

All data generated or analyzed during this study are included in this published article and its additional files.

\section{Ethics approval and consent to participate}

Not applicable.

\section{Consent for publication}

Not applicable.

\section{Competing interests}

The authors declare no conflict of interest.

\section{Author details}

${ }^{1}$ Key Laboratory of Eco-Environments in Three Gorges Reservoir Region of Ministry of Education, School of Life Sciences, Southwest University, Chongqing 400715, People's Republic of China. ${ }^{2}$ School of Energy and Environment Science, Yunnan Normal University, Kunming 650092, People's Republic of China. ${ }^{3}$ Key Laboratory of Plant Resource Conservation and Germplasm Innovation, School of Life Sciences, Southwest University, Chongqing 400715 , China.

Received: 8 June 2020 Accepted: 21 September 2020

Published online: 06 October 2020

\section{References}

Farraj A, Elshikh DA, Khulaifi MS, Hadibarata MM, Yuniarto T, Syafiuddin A (2019) Biotransformation and Detoxification of Anthraquinone Dye Green 3 using halophilic Hortaea sp. Int Biodeter Biodegrad 140:72-77. https:// doi.org/10.1016/j.ibiod.2019.03.011

Ali H (2010) Biodegradation of synthetic dyes_-a review. Water Air Soil Pollut 213(1-4):251-273. https://doi.org/10.1007/s11270-010-0382-4

Almeida EJ, Corso CR (2018) Decolorization and removal of toxicity of textile azo dyes using fungal biomass pelletized. Int J Environ Sci Technol 16(3):1319-1328. https://doi.org/10.1007/s13762-018-1728-5

Asad S, Amoozegar MA, Pourbabaee AA, Sarbolouki MN, Dastgheib SM (2007) Decolorization of textile azo dyes by newly isolated halophilic and halotolerant bacteria. Bioresour Technol 98(11):2082-2088. https://doi. org/10.1016/j.biortech.2006.08.020

Asgher M, Ramzan M, Bilal M (2016) Purification and characterization of manganese peroxidases from native and mutant Trametes versicolor IBL-04. Chin J Catal 37(4):561-570. https://doi.org/10.1016/S1872r2067 (15)61044S1

Bankole PO, Adekunle AA, Govindwar SP (2018) Enhanced decolorization and biodegradation of acid red 88 dye by newly isolated fungus, Achaetomium strumarium. J Environ Chem Eng 6(2):1589-1600. https://doi. org/10.1016/j.jece.2018.01.069

Barapatre A, Aadil KR, Jha H (2017) Biodegradation of malachite green by the ligninolytic fungus Aspergillus flavus. Clean-Soil Air Water 45(4):1-12. https ://doi.org/10.1002/clen.201600045

Bumpus JA, Brock BJ (1988) Biodegradation of crystal violet by the white rot fungus Phanerochaete-Chrysosporium. Appl Environ Microbiol 54(5):1143-1150

Casas N, Parella T, Vicent T, Caminal G, Sarra M (2009) Metabolites from the biodegradation of triphenylmethane dyes by Trametes versicolor or laccase. Chemosphere 75(10):1344-1349. https://doi.org/10.1016/j.chemo sphere.2009.02.029

Chaudhry MT, Zohaib M, Rauf N, Tahir SS, Parvez S (2014) Biosorption characteristics of Aspergillus fumigatus for the decolorization of triphenylmethane dye acid violet 49. Appl Microbiol Biotechnol 98(7):3133-3141. https ://doi.org/10.1007/s00253-013-5306-y

Chen SH, Chew YL, Ng SL, Ting ASY (2019a) Biodegradation of triphenylmethane dyes by non-white rot fungus Penicillium simplicissimum: Enzymatic and toxicity studies. Int J Environ Res 13(2):273-282. https://doi. org/10.1007/s41742-019-00171-2

Chen SH, Cheow YL, Ng SL, Ting ASY (2019b) Removal of triphenylmethane dyes in single-dye and dye-metal mixtures by live and dead cells of metal-tolerant Penicillium simplicissimum. Separ Sci Technol. https://doi. org/10.1080/01496395.2019.1626422

Chen SH, Ting Y (2015) Biosorption and biodegradation potential of triphenylmethane dyes by newly discovered Penicillium simplicissimum isolated from indoor wastewater sample. Int Biodeterior Biodegrad 103:1-7. https ://doi.org/10.1016/j.ibiod.2015.04.004

Chen SH, Su A, Ting Y (2015) Biodecolorization and biodegradation potential of recalcitrant triphenylmethane dyes by Coriolopsis sp. isolated from compost. J Environ Manage 150:274-280. https://doi.org/10.1016/j.jenvm an.2014.09.014

Chen SH, Cheow YL, Ng SL, Ting ASY (2019c) Mechanisms for metal removal established via electron microscopy and spectroscopy: a case study on metal tolerant fungi Penicillium simplicissimum. J Hazard Mater 362:394-402. https://doi.org/10.1016/j.jhazmat.2018.08.077

Chew SY, Ting ASY (2016) Common filamentous Trichoderma asperellum for effective removal of triphenylmethane dyes. Desal Water Treat 57(29):13534-13539. https://doi.org/10.1080/19443994.2015.1060173

Daneshvar N, Ayazloo M, Khataee AR, Pourhassan M (2007) Biological decolorization of dye solution containing Malachite Green by microalgae Cosmarium sp. Bioresour Technol 98:1176-1182. https://doi.org/10.1016/j. biortech.2006.05.025

Duan Z, Shen R, Liu B, Yao M, Jia R (2018) Comprehensive investigation of a dye-decolorizing peroxidase and a manganese peroxidase from /rpex lacteus F17, a lignin-degrading basidiomycete. AMB Express 8:1-16. https ://doi.org/10.1186/s13568-018-0648-6

Huang Q, An H, Song H, Mao H, Shen W, Dong J (2015) Diversity and biotransformative potential of endophytic fungi associated with the medicinal plant Kadsura angustifolia. Res Microbiol 166(1):45-55. https://doi. org/10.1016/j.resmic.2014.12.004

Jasinska A, Rozalska S, Bernat P, Paraszkiewicz K, Dlugonski J (2012) Malachite green decolorization by non-basidiomycete filamentous fungi of Penicillium pinophilum and Myrothecium roridum. Int Biodeter Biodegrad 73:33-40. https://doi.org/10.1016/j.ibiod.2012.06.025

Kalpana D, Velmurugan N, Shim JH, Oh BT, Senthil K, Lee YS (2012) Biodecolorization and biodegradation of reactive Levafix Blue E-RA granulate dye by the white rot fungus Irpex lacteus. J Environ Manage 111(2012):142-149. https://doi.org/10.1016/j.jenvman.2012.06.041

Kaushik P, Malik A (2009) Fungal dye decolourization: recent advances and future potential. Environ Int 35(1):127-141. https://doi.org/10.1016/j. envint.2008.05.010 
Kornillowicz-Kowalska T, Wrzosek M, Ginalska G, Iglik H, Bancerz R (2006) Identification and application of a new fungal strain Bjerkandera adusta R59 in decolorization of daunomycin wastes. Enzyme Microbial Technol 38(5):583-590. https://doi.org/10.1016/j.enzmictec.2005.10.009

Larkin MA, Blackshields G, Brown NP, Chenna R, McGettigan PA, McWilliam H (2007) Clustal W and Clustal X version 2.0. Bioinformatics 23:2947-2948. https://doi.org/10.1093/bioinformatics/btm404

Lin YH, Chen L, He XB, He YQ, Zhou X (2010) Biodegradation of aniline blue dye by a fungus Mucoromycotina sp. HS-3. Microbiol China 37(12):1727-1733

Marcharchand S, Ting ASY (2017) Trichoderma asperellum cultured in reduced concentrations of synthetic medium retained dye decolourization efficacy. J Environ Manage 203:542-549. https://doi.org/10.1016/j.jenvm an.2017.06.068

Morales-Alvarez ED, Rivera-Hoyos CM, Poveda-Cuevas SA, Reyes-Guzman EA, Pedroza-Rodriguez AM, Reyes-Montano EA, Poutou-Pinales RA (2018) Malachite green and crystal violet decolorization by Ganoderma lucidum and Pleurotus ostreatus supernatant and by rGILCC1 and rPOXA 1 1B concentrates: molecular docking analysis. Appl Biochem Biotechnol 184(3):794-805. https://doi.org/10.1007/s12010-017-2560-y

Munck C, Thierry E, Grassle S, Ting SH (2018) Biofilm formation of filamentous fungi Coriolopsis sp. on simple muslin cloth to enhance removal of triphenylmethane dyes. J Environ Manage 214:261-266. https://doi. org/10.1016/j.jenvman.2018.03.025

Ortiz-Monsalve VS, Poll P, Jaramillo-Garcia E, Pegas Henriques V, A J, Gutterres M, (2019) Biodecolourization and biodetoxification of dye-containing wastewaters from leather dyeing by the native fungal strain Trametes villosa SCS-10. Biochem Eng J 141:19-28. https://doi.org/10.1016/j. bej.2018.10.002

Parshetti GK, Parshetti SG, Telke AA, Kalyani DC, Doong RA, Govindwar SP (2011) Biodegradation of crystal violet by Agrobacterium radiobacter. J Environ Sci 23(8):1384-1393. https://doi.org/10.1016/S1001 $-0742(10) 60547-5$

Parshetti GK, Telke AA, Kalyani DC, Govindwar SP (2010) Decolorization and detoxification of sulfonated azo dye methyl orange by Kocuria rosea MTCC 1532. J Hazard Mater 176:503-509. https://doi.org/10.1016/j.jhazm at.2009.11.058

Przystas W, Zablocka-Godlewska E, Grabinska-Sota E (2018) Efficiency of decolorization of different dyes using fungal biomass immobilized on different solid supports. Braz J Microbiol 49(2):285-295. https://doi.org/10.1016/j. bjm.2017.06.010

Qin D, Wang L, Han M, Wang J, Song H, Yan X, Duan X, Dong J (2018) Effects of an Endophytic Fungus Umbelopsis dimorpha on the secondary metabolites of host-plant Kadsura angustifolia. Front Microbiol 9:2845. https://doi. org/10.3389/fmicb.2018.02845

Shang NJ, Ding MJ, Dai MX, Si HL, Li SG, Zhao GY (2019) Biodegradation of malachite green by an endophytic bacterium Klebsiella aerogenes S27 involving a novel oxidoreductase. Appl Microbiol Biotechnol 103(5):2141-2153. https://doi.org/10.1007/s00253-018-09583-0

Shedbalkar U, Dhanve R, Jadhav J (2008) Biodegradation of triphenylmethane dye cotton blue by Penicillium ochrochloron MTCC 517. J Hazard Mater 157(2-3):472-479. https://doi.org/10.1016/j.jhazmat.2008.01.023
Srinivasan A, Viraraghavan T (2010) Decolorization of dye wastewaters by biosorbents: a review. J Environ Manage 91(10):1915-1929. https://doi. org/10.1016/j.jenvman.2010.05.003

Takamiya M, Magan N, Warner PJ (2008) Impact assessment of bisphenol A on lignin-modifying enzymes by basidiomycete Trametes versicolor. J Hazard Mater 154(1-3):33-37. https://doi.org/10.1016/j.jhazmat.2007.09.098

Tamura K, Peterson D, Peterson N, Stecher G, Nei M, Kumar S (2011) MEGA5: Molecular evolutionary genetics analysis using maximum likelihood, evolutionary distance, and maximum parsimony methods. Mol Biol Evol 8:2731-2739. https://doi.org/10.1093/molbev/msr121

Ting ASY, Lee MVJ, Chow YY, Cheong SL (2016) Novel exploration of endophytic Diaporthe sp. for the biosorption and biodegradation of triphenylmethane dyes. Water Air Soil Pollut 227(109):1-8. https://doi.org/10.1007/ s11270-016-2810-6

Turhan K, Durukan I, Ozturkcan SA, Turgut Z (2012) Decolorization of textile basic dye in aqueous solution by ozone. Dyes Pigments 92(3):897-901. https://doi.org/10.1016/j.dyepig.2011.07.012

Wang N, Chu Y, Wu FA, Zhao Z, Xu X (2017) Decolorization and degradation of Congo red by a newly isolated white rot fungus, Ceriporia lacerata, from decayed mulberry branches. Int Biodeterior Biodegrad 117:236-244. https://doi.org/10.1016/j.ibiod.2016.12.015

Yang XQ, Zhao XX, Liu C, Zheng YY, Qian SJ (2009) Decolorization of azo, triphenylmethane and anthraquinone dyes by a newly isolated Trametes sp. SQ01 and its laccase. Process Biochem 44(10):1185-1189. https://doi. org/10.1016/j.procbio.2009.06.015

Yang X, Zheng J, Lu Y, Jia R (2016) Degradation and detoxification of the triphenylmethane dye malachite green catalyzed by crude manganese peroxidase from Irpex lacteus F17. Environ Sci Pollut Res 23(10):9585-9597. https://doi.org/10.1007/s11356-016-6164-9

Yang Y, Jim D, Wang G, Liu D, Jia X, Zhao Y (2011) Biosorption of acid blue 25 by unmodified and CPC-modified biomass of Penicillium YW01: kinetic study, equilibrium isotherm and FTIR analysis. Colloids Surf Biointerf 88:521-526. https://doi.org/10.1016/j.colsurfb.2011.07.047

Zhang D, Yang Y, Castlebury LA, Cerniglia CE (2006) A method for the large scale isolation of high transformation efficiency fungal genomic DNA. FEMS Microbiol Lett 145:261-265. https://doi. org/10.1111/j.1574-6968.1996.tb08587.x

Zhuo R, Ma L, Fan F, Gong Y, Wan X, Jiang M, Zhang X, Yang Y (2011) Decolorization of different dyes by a newly isolated white-rot fungi strain Ganoderma sp. En3 and cloning and functional analysis of its laccase gene. J Hazard Mater 192(2):855-873. https://doi.org/10.1016/j.jhazm at.2011.05.106

\section{Publisher's Note}

Springer Nature remains neutral with regard to jurisdictional claims in published maps and institutional affiliations.

\section{Submit your manuscript to a SpringerOpen ${ }^{\circ}$ journal and benefit from:}

- Convenient online submission

- Rigorous peer review

- Open access: articles freely available online

- High visibility within the field

- Retaining the copyright to your article

Submit your next manuscript at springeropen.com 